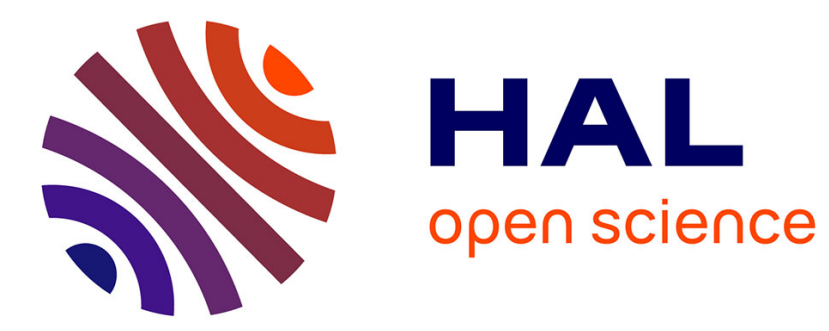

\title{
Hydro-mechanical path dependency of claystone/bentonite mixture samples characterized by different initial dry densities
}

\author{
M. Middelhoff, Olivier Cuisinier, F. Masrouri, J. Talandier
}

\section{To cite this version:}

M. Middelhoff, Olivier Cuisinier, F. Masrouri, J. Talandier. Hydro-mechanical path dependency of claystone/bentonite mixture samples characterized by different initial dry densities. Acta Geotechnica, 2021, 16, pp.3161-3176. 10.1007/s11440-021-01246-1 . hal-03268332

HAL Id: hal-03268332

https://hal.science/hal-03268332

Submitted on 23 Jun 2021

HAL is a multi-disciplinary open access archive for the deposit and dissemination of scientific research documents, whether they are published or not. The documents may come from teaching and research institutions in France or abroad, or from public or private research centers.
L'archive ouverte pluridisciplinaire HAL, est destinée au dépôt et à la diffusion de documents scientifiques de niveau recherche, publiés ou non, émanant des établissements d'enseignement et de recherche français ou étrangers, des laboratoires publics ou privés. 


\title{
Hydro-mechanical path dependency of claystone/ bentonite-mixture samples characterized by different initial dry densities
}

\author{
M. Middelhoff ${ }^{1,2 *}$, O. Cuisinier ${ }^{1}$, F. Masrouri ${ }^{1}$, J. Talandier $^{2}$ \\ ${ }^{l}$ Université de Lorraine - LEMTA, UMR 7563 CNRS, \\ (2 Rue du Doyen Marcel Roubault - BP 10162, 54000 Nancy CEDEX, France) \\ ${ }^{2}$ Agence nationale pour la gestion des déchets radioactifs (Andra), Châtenay-Malabry, France

Abstract: In the context of the French Cigéo-project, a mixture composed of $70 \%$ processed CallovoOxfordian claystone spoil and 30\% MX80-bentonite could be a potential backfill material, whose installation aims to stabilize the surrounding rock formation and to limit the propagation of the excavation damaged zone. The backfill material must sustain the overburden pressure, despite it might be exposed to different hydraulic and mechanical paths. The reference concept considers employing conventional compaction techniques, although their employment involves spatial variations in the dry density after compaction. In general, as the initial dry density has a significant impact on the hydro-mechanical behavior of backfill materials, it is of major importance to relate the variations in the initial dry density to differences in the behavior. This experimental laboratory study aimed to analyze how variations in the initial dry density affects the swelling and compression behavior of the claystone/ bentonite-mixture, in particular in unsaturated state. Further, it evaluated whether those variations affected possible hydromechanical path dependences. The experimental program comprised suction-controlled oedometer and constant-volume swelling pressure experiments, in which samples characterized by different initial dry densities were exposed to different hydro-mechanical paths. The analysis of microstructural and water retention characteristics complemented the program. Major results indicated that the magnitude of swelling pressure at a given suction depends considerably on the initial dry density, but it is independent of the imposed hydro-mechanical path. Interestingly, the dependency of the yield behavior on the hydromechanical path appears to be more pronounced as the initial dry density increases. 
29 Keywords: Callovo-Oxfordian claystone, MX80-bentonite, Microstructure, Water retention curve, Hy-

30 dro-mechanical behavior, Hydro-mechanical load path dependency

31 Acknowledgements: The authors gratefully thank Dr. N. Conil of Ineris (formerly contracted by Andra)

32 and Dr. G. Armand of Andra for fruitful discussions that helped to improve this article. Also, the authors

33 thank Dr. S. Gaboreau of BRGM with regard to the performance of microstructural analyses, and Mr. J.

34 Tisot, of LEMTA with regard to the monitoring of swelling pressure and oedometer experiments.

35

36 


\section{Introduction}

In the context of the French Cigéo-project, different materials are studied as to whether

4 they could be employed to backfill drifts and shafts of the future repository for radioactive waste located at a depth of approximately $500 \mathrm{~m}$ in the clay-rich Callovo-Oxfordian sedimentary rock formation, henceforth referred to as Callovo-Oxfordian (COX) claystone formation [5]. The installation of backfill aims to stabilize the surrounding rock formation and to limit the propagation of the excavation damaged zone (EDZ) that arises from the excavation of drifts and shafts and lowers the integrity of the repository system. The backfill must thus exhibit such a swelling pressure and compressibility that it sustains the overburden pressure upon terminat-

11 ing the closure phase. As depicted in Fig. 1, the backfill might undergo different combinations of hydraulic and mechanical paths. The path A - C (-D) describes a possible case of (stepwise) backfill material saturation under constant-volume conditions. It might be followed by loading through the overburden pressure, whose onset occurs once convergence processes cause the partial degradation of the concrete lining. Under laboratory conditions, the path $\mathrm{A}-\mathrm{C}$ corresponds to the path imposed in constant-volume swelling pressure experiments, whereas path A $-\mathrm{B}-\mathrm{C}-\mathrm{D}$ is imposed in oedometer experiments.

A potential backfill material is a mixture composed of processed Callovo-Oxfordian claystone spoil and MX80-bentonite, whose dominant mineralogical constituents are phyllosilicates (e.g. smectites, illite, illite/ smectite mixed layer minerals) [7, 21]. Since conventional compaction techniques are presumably employed to compact it to the maximum dry density at the optimum water content in situ, the material is initially characterized by a degree of saturation greater than $80 \%$ and low suctions. The initial dry density determines not only the hydro-mechanical behavior of smectite-containing materials, but also their microstructural and water re- 
dry density affect the behavior of such materials upon imposing different hydraulic and mechanical paths and their combinations.

In general, there is a wealth of studies aiming to analyze the microstructural and water retention characteristics and volume-change behavior of smectite-containing materials, in particular in unsaturated conditions $[15,19,23,27,34,36]$.

Unsaturated smectite-containing materials are characterized by micro- and macropores, referring to pores between clay aggregates and soil aggregates, respectively. Mechanical and hydraulic loads affect differently those pore populations. Densification reduces only the amount of macropores, whereas the amount of micropores remains stable [e.g. 37]. Hydration affects both pore populations as the amount of micropores increases and the amount of macropores decreases due to the swelling of smectite particles [e.g. 27].

The structure determines the water retention characteristics of smectite-containing materials. Densification provokes a shift of the air entry value (AEV) to higher suction values as it reduces the size and shape of macropores. The initial dry density affects those characteristics, only if suction values are lower than few hundred MPa. Below those suction values, dominant capillary phenomena are controlled by macropores [e.g. 15].

Among others, Lloret et al. [23] studied the volume-change behavior of FEBEX-bentonite in unsaturated conditions. Their experimental program comprised suction-controlled oedometer and constant-volume swelling pressure experiments under different hydro-mechanical paths. Experimental protocols considered the preparation of samples at the hygroscopic water content. Oedometer experiments were conducted on samples, which were characterized by one initial dry density, whereas samples studied in constant-volume swelling pressure experiments were compacted to different initial dry densities. Oedometer experiments indicated that the material rigidified and the yield stress shifted to higher vertical stresses as the suction was increased. The material response considerably depended on the hydro-mechanical path attributable to a 
differently evolving microstructure. The imposition of a wetting-loading sequence involves an initial increase in total porosity due to material swelling. Pore-merging accounts for the fact that the mechanical loading affects all pores. A loading-wetting sequence reduces the macroporosity during mechanical loading and the later collapse of the majority of macropores limits material swelling upon wetting. The former sequence thus yields a greater final total porosity than the latter. There are only a few studies aiming to determine the impact of variations in the initial dry density on the yield behavior of smectite-containing materials upon hydro-mechanical loading. Nowamooz and Masrouri [30] studied the saturated and unsaturated compression behavior of silt/ bentonite-mixtures by means of suction-controlled oedometer experiments. Sample preparation comprised their compaction to different dry densities at the optimum water content. At a given suction, the yield stress increases as the initial dry density increases, and, at a given initial dry density, the material rigidifies as the suction increases. There is still little understanding about whether variations in the initial dry density alter the yield behavior of smectite-containing materials upon hydro-mechanical loading, and how they affect possible hydro-mechanical path dependencies.

Suction-controlled constant-volume swelling pressure experiments of Lloret et al. [23] showed that the evolution of swelling pressure was characterized by a double peak pattern upon stepwise decreasing suctions. The characteristic pattern evolved, regardless of the initial dry density. The first maximum value was attributed to the initial swelling of smectite particles, which was followed by the partial collapse of soil aggregates indicating the yield stress. The second maximum value ensued as the swelling of particles prevails over the collapse of soil aggregates. Romero [33] conducted similar experiments on Boom-clay samples and hypothesized that the yield loci determined in suction-controlled oedometer and constant-volume swell- 
ing pressure experiments must coincide. However, only a few studies corroborated the hypothesis [e.g. 4]. Further, there are no information about whether variations in the dry density affect the coincidence.

Experiment results are commonly interpreted and reproduced by adopting the constitutive models proposed in Alonso et al. [2] (Barcelona Basic Model (BBM)) and Alonso et al. [3] (Barcelona Expansive Model (BExM)). The latter acknowledges the existence of micro- and macropores and is thus capable to reproduce the characteristic features of smectite-containing materials. As respective experimental studies are scarcely available, only a few constitutive models allow to consider the impact of variations in the initial dry density on the hydro-mechanical behavior $[38,43]$.

In the context of in situ compacted backfill materials, this study aimed to evaluate the impact of variations in the initial dry density on the response of the claystone/ bentonite-mixture to different hydro-mechanical paths. Moreover, it analyzed whether those variations affect the postulated coincidence of yield loci. The evaluation was accomplished by conducting suctioncontrolled swelling pressure and oedometer experiments on samples which were compacted to different initial dry densities at the optimum water content. Experiments were complemented by analyzing the microstructural and water retention characteristics of the potential backfill material. Obtained results can be useful to improve existing constitutive models regarding the integration of the impact of the initial dry density.

\section{Material}

Following, the section recapitulated the general characteristics of the mixture studied (e.g. physical characteristics, physico-chemical characteristics, compaction characteristics), and described its microstructural and water retention characteristics afterwards. 


\subsection{General characteristics}

The mixture studied was composed of $70 \%$ processed Callovo-Oxfordian (COX) claystone spoil and 30\% MX80-bentonite in weight. The latter was limited to $30 \%$ in order to reduce mineralogical and physico-chemical incompatibilities between the potential backfill material and the surrounding rock formation. Callovo-Oxfordian claystone spoil arose during the excavation of drifts of Andra URL at a depth of - 490 m (Bure, Meuse/ Haute-Marne region, France). The subsequent processing comprised its crushing and sieving to a maximum grain diameter of $2 \mathrm{~mm}$. The processed material was stored in airtight containers afterwards. Henceforth, processed COX-claystone spoil is referred to as $\mathrm{COX}_{\mathrm{c}}$. At that depth, intact COX-claystone contains $27 \%$ carbonates (e.g. calcite, dolomite), $46 \%$ phyllosilicates (e.g. smectites, illites), $24 \%$ tectosilicates (e.g. quartz, feldspars), and minor fraction of other mineral phases [7]. Likewise, MX80-bentonite (Wyoming, USA) was crushed and sieved to maximum grain diameters of $2 \mathrm{~mm}$ and filled into air-tight containers. The dominant mineral phases are phyllosilicates (e.g. smectites), whose fraction is about $84 \%$. The mineralogical composition is completed by tectosilicates (e.g. quartz) [21] .

The mixture was characterized by an initial water content $\left(w_{i n i}\right)$, liquid limit $(L L)$, plastic limit $(P L)$ and specific gravity $\left(G_{s}\right)$ of $6.4 \%, 112.5 \%, 34.7 \%$, and 2.64 , respectively [25]. Its cation exchange capacity $(C E C)$ of $39 \mathrm{meq} / 100 \mathrm{~g}$ and specific surface area (SSA) of $32 \mathrm{~m} / \mathrm{g}$ were determined by means of the cobalt hexamine method [32] and the BET-method [17], respectively. The cobalt hexamine method also revealed that the exchangeable cation species were dominated by $\mathrm{Na}^{+}$- and $\mathrm{Ca}^{2+}$-ions. An elevated compaction energy increased the maximum dry density $\left(\rho_{d, \max }\right)$ and decreased the optimum water content $\left(w_{\text {opt }}\right)$ of the mixture [25]. Accordingly, the optimum water content and maximum dry density were $29.0 \%$ and $1.45 \mathrm{Mg} / \mathrm{m}^{3}$, respectively, in the case of standard compaction energy employment, and $18.2 \%$ and $1.72 \mathrm{Mg} / \mathrm{m}^{3}$, respectively, in the case of modified compaction energy employment. The grain 
size distribution was determined by means of laser diffractometry and dry sieving and was characterized by $10 \%$ - and $60 \%$ - passing $\left(D_{10} / D_{60}\right)$ values of $0.008 \mathrm{~mm}$ and $0.8 \mathrm{~mm}$, respectively. ence between the calculatable total void ratio $\left(e_{t o t}\right)$ and the macro-void ratio and accounts for

\subsection{Microstructural characteristics}

Mercury intrusion porosimetry (MIP) experiments were conducted on samples initially compacted to dry densities of $1.72 \mathrm{Mg} / \mathrm{m}^{3}$ and $1.44 \mathrm{Mg} / \mathrm{m}^{3}$ at a water content of $18.2 \%$ in order to highlight how possible variations in the initial dry density affect the microstructure. The latter value corresponded to a reduction of the initial dry density by about $17.5 \%$ with respect to the maximum dry density. Its consideration facilitated to interpret the results of swelling pressure and oedometer experiments presented later. MIP-experiments were conducted by means of an AutoPore IV 9500 (Micromeritics, U.S.A). The MIP-technique bases on the principle of forcing a non-wetting fluid, e.g. mercury, to enter a porous medium by incrementally increasing the injection pressure. A review of the technique is given in Romero and Simms [35]. Prior to the analyzes, samples were dried by heating them up to $80^{\circ} \mathrm{C}$ under vacuum conditions. Apart from that, the experiment protocol followed that established by Cuisinier and Laloui [8]. Approaches for data processing and presentation were adopted from Juang and Holtz [20].

As depicted in Fig. 2a and Fig. 2c, pore size distribution curves of samples were characterized by two distinct peaks, regardless of the initial dry density. They corresponded to microand macropore populations. According to Romero et al. [36], the inflection point of pore size distribution curves indicated the transition from micro- to macropores. Pores, whose diameters were smaller and greater than the diameter at the inflection point, are referred to as micro- and macropores, respectively. Their quantities are expressed by the micro-void ratio $\left(e_{m}\right)$ and macro-void ratio $\left(e_{M}\right)$, respectively. The unaccountable void ratio $\left(e_{u n}\right)$ is defined as the differthe pores, whose diameter was too small or too large to be detected. 
The transition of macro- to micropores occurred at pore diameters ranging between 4 and

$1485 \times 10^{2} \mathrm{~nm}$, regardless of the initial dry density. In all cases, most micropores occurred at a pore

149 diameter of about $2 \times 10^{1} \mathrm{~nm}$. In the case of denser samples, the majority of macropores occurred

150 at a pore diameter of about $8 \times 10^{4} \mathrm{~nm}$. Interestingly, in the case of looser samples, the increasing

151 pore size distribution curve indicated that the diameter, at which the majority of macropores

152 occurred, appeared to exceed the limit of the device. Densification reduced the macro- and

153 unaccountable void ratio by about $50 \%$, whereas the micro-void ratio remained stable. The ob-

154 servation were in accordance with the literature as micropores are expected to react sensitively

155 to the hydraulic but not to the mechanical path, such as those imposed by means of the static

156 compaction method [16, 35, e.g. 36]. The differences in the unaccountable void ratio might be

157 attributed to pores, whose diameters were in the millimeter range involving the low initial dry 158 density.

159 In general, the microstructure of mixture samples comprised micro- and macropores, like

160 other smectite-containing materials. As expected, the latter pore population was significantly

161 reduced by densification. It must be thus assumed that the water retention characteristics of

162 denser and looser material differ considerably.

163

\subsection{Water retention characteristics}

Samples were characterized by initial dry densities of $1.72 \mathrm{Mg} / \mathrm{m}^{3}$ and $1.44 \mathrm{Mg} / \mathrm{m}^{3}$ and a water content of $18.2 \%$. A range between few tens of $\mathrm{kPa}$ to some hundreds of MPa were imposed by combining the osmotic and vapor equilibrium technique. Their individual ranges overlapped at suctions of about $7 \mathrm{MPa}$ [e.g. 9, 31]. The former technique bases upon the principle that water molecules can go through a semipermeable membrane and move from the pore solution to a macro-molecular (polyethylene glycol (PEG)) solution and vice versa. The migration and its direction is driven by a concentration gradient. Suction is functionally related to the concentration of PEG-molecules in solution as their concentration determines the magnitude of 
the gradient. A review of the technique is given in Delage and Cui [10]. The vapor equilibrium

173 technique adopts Kelvins equation relating suction to the relative humidity in a closed system.

174 The closed system comprises a gas phase and a liquid phase, whose specific solutes control the

175 relative humidity in the adjacent gas phase. In general, saturated salt solutions are employed as

176 a liquid phase. A review of the technique is given in Delage et al. [12] and Delage et al. [13].

177 As depicted in Fig. 3, denser samples were initially characterized by lower void ratios

178 and higher degrees of saturation due to the higher initial dry density. Upon hydration, the void

179 ratio and degree of saturation of looser and denser samples increased comparably. Drying had

180 no considerable consequences on both sample types with regard to their void ratios. It affected

181 the degree of saturation of denser samples more significantly than that of looser samples.

182 The impact of variations in the initial dry density appeared to vanish when imposed suc-

183 tion exceeded values of $200 \mathrm{MPa}$. This observation was in accordance with the results of mi-

184 crostructural analysis as the vanishing impact of initial dry density indicated the existence of

185 micro- and macropores (Fig. 2). The imposition of a suction higher than $200 \mathrm{MPa}$ involved the

186 fact that residual water was available only in micropores, whose size and shape were insensitive

187 to compaction and varying initial dry densities. According to the different diffuse double layer

188 theories, electrostatic interactions between the water molecules and the clay mineral surfaces

189 account for a complete immobilization of the residual water in micropores [e.g 34].

190 In general, the water retention characteristics of differently dense mixture samples con-

191 firmed the results of microstructural analysis as the vanishing impact of initial dry density at

192 high suctions indicated the existence of micro-and macropores.

1933 Oedometer and constant-volume swelling pressure experiments

194 The unsaturated compression and swelling behavior were studied by conducting oedom-

195 eter and constant-volume swelling pressure experiments, in which the suction was controlled

196 by means of the osmotic technique. Further, different hydro-mechanical paths were imposed to 
analyze the impact of variations in the dry density on possible path dependencies. The experiment approach considering variations in the initial dry density, the sample preparation, the experiment protocols, and the experiment program are described below.

\subsection{Approach}

Full-scale experiments conducted in situ (e.g. the "Backfill and Plug Test" [18], the "Prototype repository" [6]) highlighted the issues involving the employment of conventional compaction techniques to install smectite-containing backfill materials in situ. Their experiment protocols envisaged compacting backfill materials to the maximum dry density at the optimum water content in a layer-wise manner. Highest swelling pressure and lowest compressibility were expected to be reached by this means [e.g. 26]. Unlike the initial water content, whose value remained stable in the cross section of the drift, the initial dry density decreased by up to $20 \%$ with respect to the maximum dry density. They attributed this finding to a loss of compaction energy ensuing as the handling of the compactor became difficult, in particular close to the drift top and drift walls.

In order to portray spatial variations in the initial dry density, samples were compacted to the maximum dry density of $1.72 \mathrm{Mg} / \mathrm{m}^{3}$ at the optimum water content of $18.2 \%$, which was obtained by means of modified Proctor experiments. They were complemented by samples characterized by dry densities of $1.66 \mathrm{Mg} / \mathrm{m}^{3}, 1.59 \mathrm{Mg} / \mathrm{m}^{3}$, and $1.44 \mathrm{Mg} / \mathrm{m}^{3}$ and a water content of $18.2 \%$. The values corresponded to a reduction of the dry density by $2.5 \%, 7.5 \%$ and $17.5 \%$, respectively, with respect to the maximum dry density.

\subsection{Sample preparation}

The material was prepared at the optimum water content and then filled in an airtight container. Deaired/ demineralized water was added in order to reach the optimum water content [25]. Samples were compacted to the different dry densities at the optimum water content by means of the static compaction method at a controlled deformation rate of $0.1 \mathrm{~mm} / \mathrm{s}$. Samples, 
whose microstructural and water retention characteristics were previously presented, were similarly prepared. Henceforth, the type indicates the initial dry density of samples. Their initial characteristics are compiled in Table 1.

\subsection{Suction-controlled oedometer experiments}

The protocol of suction-controlled oedometer experiments considered samples of all types. The cell employed in suction-controlled oedometer experiments was composed of a piston, mold, and base (e.g. Delage et al. [11] or Nowamooz and Masrouri [29] for further information about its design). The base was characterized by one inlet, one outlet and a mesh, so solutions could be circulated beneath the mesh. It covered a groove spiraling to the center axis of the cylindrical cell and connecting the inlet and outlet. In combination with a semi-permeable membrane separating the sample from the mesh, the design allowed to adopt the osmotic technique in order to impose suctions. The oedometer allowed to apply vertical stresses of up to $3000 \mathrm{kPa}$. PEG-reservoirs were placed in temperature-controlled baths in order to minimize temperature effects.

\subsection{Suction-controlled constant-volume swelling pressure experiments}

Samples of all types were considered in order to study the evolution of swelling pressure upon stepwise hydration. The constant-volume swelling pressure cell proposed by Yigsaw et al. [40] was similarly designed allowing to adopt the osmotic technique. However, a porous disc was employed instead of the mesh, and the piston was substituted for a lid, which contained the load sensor. By eventually screwing the components together, a pre-stress of $50 \mathrm{kPa}$ was imposed.

\subsection{Hydro-mechanical paths and experimental program}

The protocol of suction-controlled swelling pressure and oedometer experiments comprised different hydro-mechanical paths depicted in Fig. 4 and Fig. 5, respectively. Their imposition aimed to determine how different paths affect the swelling and compression behavior of 
the potential backfill material, in particular in unsaturated conditions. Since backfill materials

248 are not expected to undergo drying, hydration referred exclusively to the (stepwise) saturation

249 of the mixture, whose initial suction was about $2700 \mathrm{kPa}$ (Table 1).

Hydro-mechanical paths A, B, C, and D differed in the magnitude of the initial hydration

step followed by stepwise mechanical loading and unloading. Hydro-mechanical loads were changed when strains stabilized at rates lower than $0.5 \%$ (of the initial sample height) per day.

Hydro-mechanical paths E, F, and $\mathrm{G}$ differed in the number of stages, in which different

suctions were imposed. Imposed suctions were decreased when the swelling pressure stabilized at rates lower than $5 \mathrm{kPa}$ per day.

Henceforth, samples are identifiable by means of their sample type and imposed hydromechanical paths. The prefix refers to the sample type, whereas the imposed hydro-mechanical path is indicated by the suffix. For instance, sample I - D was characterized by an initial dry density of $1.72 \mathrm{Mg} \mathrm{m}^{-3}$, whose compression behavior was analyzed by adopting hydro-mechanical path D (Fig. 4). The experiment program developed is described in Table 2.

It was believed that this comprehensive experimental program allowed to evaluate how variations in the initial dry density affect the behavior of a potential backfill material under 263 different hydro-mechanical paths.

\section{Results}

Following, the results of suction-controlled oedometer and constant-volume swelling pressure experiments are presented. Since the free-swell potential experiments represented the first stage of oedometer experiments, their results are described in the corresponding section.

\subsection{Suction-controlled oedometer experiments}

Oedometer experiments were conducted on type I- to type IV-samples by imposing hy-

270 dro-mechanical paths A to D. They were aimed at studying how the one-dimensional compres-

271 sion behavior of the mixture varies as response to the different initial dry densities of samples 
and imposed hydro-mechanical paths. Additionally, information about the free-swell potential were provided. Their results are depicted in Fig. 6a to Fig. 6h. For clarification purpose, the presentation of the results obtained while unloading is omitted.

Compression curves were characterized by two or three zones, in which the slope of the compression line changed. Hydro-mechanical paths $\mathrm{C}$ and D involved two zones, whereas the imposition of hydro-mechanical paths A and B implied the development of three zones constituting s-shaped compression curves. Compression lines converged as net vertical stresses were increased beyond about $1000 \mathrm{kPa}$. Those characteristics were observed, regardless of the initial dry density of samples. The intersection of compression curves of less dense samples cannot be reasonably explained, yet (compare Fig. 6h). In elastoplastic frameworks [e.g. 2], the first and second zones are referred to as the elastic and plastic domains, which are separated by the yield stress. Deformations in the elastic domain appeared to be little affected by varying initial dry densities, whereas decreasing suctions involved greater elastic deformations. Deformations in the plastic domain became less pronounced as initial dry densities and imposed suctions increased. In addition, similarly dense samples exhibited smaller plastic deformations in response to increasing suctions. Among the different sample types, yield stresses appeared to converge as initially imposed suctions were reduced.

Oedometer experiments also indicated that the free-swell potential increased as the initial dry density was increased, in particular upon imposing lower initial suctions.

In general, the initial dry density affected the one-dimensional compression behavior of mixture samples more considerably when higher suctions were imposed. In saturated state, compression curves appeared to be comparable with regard to their characteristics and shape. The free-swell potential was considerably affected by the initial dry density, in particular in ranges of lower suctions. 


\subsection{Suction-controlled constant-volume swelling pressure experiments}

Constant-volume swelling pressure cells controlling suction by means of the osmotic technique were employed in order to study the swelling pressure evolution of the mixture under different hydro-mechanical paths. Evolution of swelling pressure recorded are depicted in Fig. $7 \mathrm{a}$ and Fig. $7 \mathrm{~b}$.

In the case of sample II-E, the evolution was not measured due to a malfunction of the load sensor. It still became evident in Fig. 7a that the stabilized swelling pressure at each suction stage increased as the initial dry density increased. The pattern of the curves was generally characterized by a post-peak stabilization at lower or comparable stresses. In the cases of type III- and IV-samples, the decrease of swelling pressure occurred upon imposing a suction smaller than $1000 \mathrm{kPa}$, whereas, in the case of the type I-sample, there was only a slight reduction and ensued when suctions were smaller than $100 \mathrm{kPa}$. As highlighted in Fig. 7b, the mixture reacted to the imposition of different hydration paths identically, since the stabilized swelling pressures at the corresponding suction stages differed negligibly.

In general, suction-controlled constant-volume swelling pressure experiments revealed that the unsaturated swelling pressure of the mixture depended on the initial dry density rather than on the hydraulic path. Further, the results depicted in Fig. 7b indicated a good repeatability of swelling pressure experiments.

\section{Discussion}

The discussion adopted the elastoplastic frameworks proposed in Alonso et al. [2] and Alonso et al. [3]. It analyzed how variations in the initial dry density affect the compression and swelling behavior of mixture samples. The first and second sections are followed by a comparison which evaluated how those variations alter the response of materials to the different hydromechanical paths, in particular the yield behavior. Although representing the first stage of the suction-controlled oedometer experiments, it appears to be more suitable to discuss the results 
of free-swell potential experiments in conjunction with those of the swelling pressure experiments.

\subsection{Compression behavior}

Suction-controlled oedometer experiments indicated that the shape of compression curves depended on the hydro-mechanical path, in particular on the initially imposed wetting. The dependency was observed, regardless of the initial dry density. The imposition of hydro-mechanical paths $\mathrm{C}$ and $\mathrm{D}$ led to compression curves characterized by the elastic and plastic domain. In contrast, s-shaped compression curves ensued through the imposition of hydro-mechanical paths A and B. Their nonlinear compression behavior in the plastic domain disagreed with the formulation of the virgin compression line, whose slope is described by the parameter $\lambda(s)$ [2]. The applicability of the framework thus appeared to be limited.

In general, at a given suction, loading induces the collapse of macropores, and in turn, increases the degree of saturation. In other words, unsaturated samples could saturate through compaction [e.g. 28]. The nonlinear behavior might be related to the fact that the compressibility varied as the degree of saturation increased [e.g. 44]. Models proposed in Gallipoli et al. [14] and Zhou et al. [44] relate the compressibility to the degree of saturation, instead of suction. By this means, they allow to describe the transition of the compressibility in unsaturated state to that in saturated state through compaction. This prediction was consistent as compression curves converged at high vertical stresses $\left(\sigma_{v} \geq 1000 \mathrm{kPa}\right)$, regardless of the imposed suction. In the context of in situ compacted backfill materials, the prediction implied a negligible impact of the saturation state on the compression behavior when the overburden pressure fully affects the backfill material.

In the frameworks proposed in Alonso et al. [2] and Alonso et al. [3], the loading-collapse (LC) curve gives the functional relation between the yield stress and imposed suction. Corresponding yield loci were derived from suction-controlled oedometer experiments. As depicted 
in Fig. 8a, the variation of yield stress with imposed suction was almost identical, in the cases

347 of type I-, II-, and III-samples. LC-curves thus coincided. Yield stresses of type IV-samples

348 were lower, in particular when hydro-mechanical paths $\mathrm{C}(\mathrm{s}=200 \mathrm{kPa})$ and $\mathrm{D}(\mathrm{s}=2000 \mathrm{kPa})$

349 were imposed. In ranges of lower suctions, the two LC-curves converged. Two conclusions can

350 be drawn from Fig. 8. At higher suctions, slight variations in the initial dry density had no

351 impact on the yield behavior. There was an apparent threshold, below which the initial dry

352 density came into effect. At lower suctions, the impact of variations in the initial dry density

353 vanished. It was manifested by the convergence of LC-curves.

354 At lower suctions, crystalline swelling and partial particle breakup ensued as the hydra-

355 tion front propagated entirely through the sample under free conditions. Collapse of macropores

356 was less probable due to the small vertical stress $\left(\sigma_{v} \approx 10 \mathrm{kPa}\right)$. The processes involved an

357 increase in micropores and a decrease in macropores as swelling particles penetrated the macro-

358 pores. Not only did pore merging turn the bimodal pore size distribution function into a uni-

359 modal one, it also increased the total porosity, regardless of the initial dry density [e.g. 41, 42].

360 In general, a unimodal pore size distribution function implies that mechanical loading affects

361 the overall structure. At lower suctions, loading in the elastic domain adapted the amount of

362 pores in all samples, as indicated by the coinciding void ratios in Fig. 8b. The pores collapsed

363 under comparable stresses, thus the stiffness of the overall structure and in turn, the yield

364 stresses appeared to converge.

365 In contrast, at higher suctions, the structure of mixture samples was characterized by mi-

366 cro- and macropores, and mechanical loading affected only the aggregates surrounding the lat-

367 ter pore population. LC-curves of type I-, II-, and III-samples might coincide due to a still com-

368 parable amount of macropores and, in turn, a similar stiffness of soil aggregates. Accordingly,

369 the elevated macroporosity in type IV-samples accounted for the lower yield stresses. It might 
be of interest to corroborate the hypothesis of comparable structures after free swelling by

371 means of microstructural investigations (e.g. MIP-experiments).

In the context of in situ compacted backfill materials, the results of suction-controlled

373 oedometer experiments highlighted that the initial dry density has an impact of the compression behavior of the mixture, in particular on the yield behavior, only if lower vertical stresses and higher suctions are imposed. If samples saturate under free-swell conditions, an adaption of the total porosity appears to involve a comparable stiffness of the overall structure.

\subsection{Swelling behavior}

Suction-controlled constant-volume swelling pressure experiments indicated that the evolution of swelling pressure was characterized by a post-peak stabilization at lower or comparable stresses. Although the increase in initial dry density accompanied an increase in swelling pressure at a given suction (Fig. 7a), there was no functional relation between initial dry density and swelling pressure.

As implied in the introduction, Lloret et al. [23] adopted parts of the elastoplastic framework proposed in Alonso et al. [3] in order to interpret the double peak pattern. The initial reduction of suction caused homogeneous swelling of particles. Increasing vertical stresses compensated for the swelling of particles as the stiffness of soil aggregates was high. Decreasing vertical stresses followed the first maximum value and indicated that the yield stress was reached. The partial collapse of macropores lowered the stiffness of soil aggregates and progressing swelling of particles cannot compensate for the collapse of macropores. As the reduction of suction reduction, swelling of particles prevailed over collapse of macropores, and increasing vertical stresses compensated for the swelling of particles again. The phenomenological interpretations proposed in Massat et al. [24] and Yigsaw et al. [40] were similar to that of Lloret et al. [23]. Yet, they specified that macrostructural rearrangements accounted for an increase in material stiffness and a consequent dominance of swelling of particles. In this study, 
the evolution of swelling pressure was characterized by a post-peak stabilization at lower or 396 comparable stresses. In the cases of type I-samples, vertical stresses stabilized at comparable 397 values after reaching the peak. Their lower initial macroporosity apparently limited the struc398 tural rearrangement, in particular the collapse of macropores. Conversely, in the cases of type III- and IV-samples, the swelling of particles appeared to be less pronounced than the collapse of macropores, thus the vertical stresses stabilized at lower stresses.

Wang et al. [39] described a potential functional relation between the imposed suction and swelling pressure which implied a monotonous increase in swelling pressure. Since they attributed this finding to the homogeneous swelling of particles and the high stability of soil aggregates, the question was raised why aggregates might be differently stable.

Middelhoff et al. [25] conducted constant-volume swelling pressure experiments on mixture samples prepared to the same initial conditions. Their experiment protocol comprised the direct saturation of samples with deaired/ deionized water. The results complemented those recently obtained and highlighted the hydraulic path independency of the material, as depicted in Fig. 9a and Fig. 9b. The independence appeared to be valid, regardless of the initial dry density of the material. Wang et al. [39] conducted similar swelling pressure experiments on compacted bentonite/ claystone-mixture samples, whose mineralogical composition was dominated by smectites. They also reported on a hydraulic path independency. According to their interpretation, the direct and stepwise saturation triggered sequentially comparable structural rearrangements and led eventually to a similar microstructure.

The protocol of suction-controlled oedometer experiments comprised the determination 416 of the free-swell potential of mixture samples at their initial stage. The relationship between the 417 initial dry density and free-swell potential of samples can be described by a linear function, 418 whose slope increased logarithmically as the suction decreases. In the case of suctions being equal to $2000 \mathrm{kPa}$, no swelling was observed. Presumably, the increasing smectite mass in 
denser samples caused the linear relation since each particle can undergo crystalline swelling 421 and particle breakup under the availability of water molecules [e.g. 22]. Major macrostructural rearrangements were less probable due to the low initial vertical load.

that stepwise wetting involved a non-monotonic increase in swelling pressure, regardless of the initial dry density. The post-peak stabilization at lower or comparable stresses was attributed to structural rearrangements, in particular particle swelling and partial macropore collapse. In the case of denser samples, the latter aspect might account for the stabilization at comparable macropores therein. The evolution of swelling pressure was hydraulic path independent potentially attributable to a similar final microstructure. The free-swell potential experiments indicated a functional relation between the initial dry density and final free-swell potential at a given suction. It was attributed to the availability of water molecules and the larger amount of smectite particles in denser samples.

\subsection{Comparison of yield behavior}

As described above, the (suction-controlled) propagation of the hydration front through the sample under constant-volume conditions involved the initial swelling of particles, followed by the collapse of aggregates and the final dominance of particle swelling over aggregate collapse. The swelling pressure evolved in conjunction with those structural rearrangements. In contrast, under oedometric conditions, structural rearrangements were terminated before load-

440 ing. The differently rearranging structure might account for the fact that the yield loci of denser 441 samples differed significantly, whereas those of looser samples coincided, as depicted in $442 \quad$ Fig. 10.

443 In the case of type I- and III-samples, the partial collapse of aggregates and the subsequent 444 swelling of particles appeared to increase the density of the material and, in turn, the stiffness 
of the overall structure [24]. Their yield stress increased as a consequence. Type IV-samples

446 were characterized by an elevated fraction of macropores, and their partial collapse cannot be 447 compensated by the swelling of particles. The densification was less effective, and the stiffness 448 of the overall structure measured under constant-volume conditions became comparable to that 449 determined under oedometric conditions. Indeed, the findings partially corroborated the hy450 pothesis suggested by Romero [33] as the yield loci of looser samples coincided. However, the 451 yield behavior of denser samples appeared to considerably depend on the hydro-mechanical 452 path. Conclusion

453 The French reference considers a mixture composed of $70 \%$ processed Callovo-Oxfor454 dian claystone spoil and 30\% MX80-bentonite to be a material, which could be potentially em455 ployed to backfill drifts and shafts of the future repository for intermediate- and high-level ra456 dioactive waste in the clay-rich Callovo-Oxfordian sedimentary rock formation. Regardless of 457 the saturation state, the convergence of the surrounding rock formation likely induces mechan458 ical loading. Thus, the occurrence of different hydro-mechanical paths is possible. Installed by 459 means of conventional compaction methods, the backfill material is likely characterized by 460 spatial variations in its initial dry density. Since the initial dry density is one of the factors 461 controlling the water retention characteristics and hydro-mechanical behavior of smectite-containing material, it is of major relevance to analyze the impact of its variations on the performance of claystone/ bentonite-mixtures, in particular in unsaturated state.

At its initial stage, this laboratory experimental program analyzed the mixture with regard 465 to its microstructural and water retention characteristics. Subsequent suction-controlled oedom466 eter and constant-volume swelling pressure experiments aimed to evaluate how variations in 467 the initial dry density affect the compression and swelling behavior. The final comparison of experiment results revealed whether the hydro-mechanical behavior of the mixture depends on 
the hydro-mechanical path, and whether variations in the dry density have an impact on possible

470 dependencies. Following conclusions can be drawn from the experiments conducted:

471 1. The results of microstructural analysis agreed with the trends generally described in the literature. In contrast to micropores, whose amount remained stable, macropores were considerably affected by densification. A reduction of dry density by about $20 \%$ decreased their amount by about $50 \%$.

2. As expected, water retention characteristics highlighted the existence of micro- and macropores since the impact of the initial dry density vanished at higher suctions. The observation was related to the fact that micropores control capillary phenomena at higher suctions.

3. The impact of the initial dry density on the compression behavior of mixture samples vanished when higher vertical stresses or lower suctions were imposed. Although suctions were imposed, the compression curves of unsaturated samples converged into those of

4. At a given suction, the free-swell potential of the mixture was linearly related to the initial dry density. In turn, the slope of this linear function varied logarithmically with the imposed suction. The findings were attributed to the larger amount of smectite particles in denser samples and to the greater availability of water molecules at lower suctions.

5. Suction-controlled hydration of mixture samples under constant-volume conditions involved the evolution of swelling pressure, whose development was characterized by a post-peak stabilization at lower or comparable stresses. The pattern evolved regardless of the initial dry density and was attributed to rearrangements at the micro- and macrostructural level. The swelling pressure increased with increasing initial dry density at a given suction. Apart from those findings, experiments revealed that the evolution of swelling 
pressure was independent of the hydraulic path potentially attributable to a similar final microstructure.

495 6. The comparison of results highlighted that the initial dry density of samples had an impact on their hydro-mechanical path dependency. In the case of looser samples, the yield behavior under constant-volume and oedometric conditions was comparable, whereas, in the case of denser samples, the yield stresses were shifted to lower values under oedometric conditions. The difference in yield locus position was attributed to an adaption of the total porosity and a comparable stiffness of the overall structure.

This study confirmed that the microstructural and water retention characteristics of the claystone/ bentonite-mixture considerably changed as a response to variations in their initial dry 503 density. Variations in the initial dry density had a significant impact on the swelling behavior 504 of the mixture, regardless of the saturation state. Regarding the compression behavior, the im505 pact vanished as lower suctions or higher vertical stresses were imposed. In the context of in situ compacted backfill materials, neither the initial dry density nor the saturation state accord-

507 ingly have an impact on the compression behavior when the material is subjected to the over508 burden pressure once the concrete lining degrades. The evolution of swelling pressure under 509 constant-volume conditions was hydraulic path independent, whereas the yield behavior was 510 hydro-mechanical path independent only when the initial dry density of the material was lower. 511 Regarding future laboratory experimental studies, it might be of interest to corroborate the hy512 pothesis of the comparable stiffness of the overall structure by complementing the different 513 stages in oedometer experiments by means of X-ray tomography. 


\section{Funding}

515 The work presented in this paper has been carried out during the preparation of the $\mathrm{PhD}$ thesis

516 of the first author, which is funded by Andra (France), the French agency in charge of the man-

517 agement and disposal of nuclear waste.

\section{Conflicts of interest}

519 The authors wish to confirm that there are no known conflicts of interest associated with this

520 publication and there has been no significant financial support for this work that could have

521 influenced its outcome.

\section{Availability of data and material}

523 The datasets generated during and/or analysed during the current study are available from the

524 corresponding author on reasonable request.

\section{Author's contributions}

526 Conceptualization: Marvin Middelhoff, Olivier Cuisinier, Farimah Masrouri, Jean Talandier;

527 Methodology: Marvin Middelhoff, Olivier Cuisinier, Farimah Masrouri, Jean Talandier; For-

528 mal analysis and investigations: Marvin Middelhoff; Writing - original draft preparation:

529 Marvin Middelhoff; Writing - review and editing: Marvin Middelhoff, Olivier Cuisinier,

530 Farimah Masrouri, Jean Talandier; Funding acquisition: Olivier Cuisinier, Farimah Masrouri,

531 Jean Talandier; Resources: Jean Talandier; Supervision: Olivier Cuisinier, Farimah Masrouri,

\section{Jean Talandier}


536 1. Alonso EE, Gens A, Whight D (1987) General report. In: Hanrahan ET, Orr TLL, Widdis TF (eds) Groundwater Effects in Geotechnical Engineering. A. A. Balkema, Rotterdam, Brookfield, pp 1087-1146

2. Alonso EE, Gens A, Josa A (1990) A constitutive model for partially saturated soils. Géotechnique 40:405-430. doi: 10.1680/geot.1990.40.3.405

3. Alonso EE, Vaunat J, Gens A (1999) Modelling the mechanical behaviour of expansive clays. Engineering Geology 54:173-183. doi: 10.1016/S0013-7952(99)00079-4

4. Alonso EE, Romero E, Hoffmann C et al. (2005) Expansive bentonite-sand mixtures in cyclic controlled-suction drying and wetting. Engineering Geology 81:213-226. doi: 10.1016/j.enggeo.2005.06.009

5. ANDRA (2005) Dossier 2005 Argile Synthesis. Evaluation of the feasibility of a geological repository in an argillaceeous formation. Meuse/ Haute-Marne site. Collection les Rapports, vol 268. ANDRA, Châtenay-Malabry

6. Börgesson L, Gunnarsson D, Johannesson L-E et al. (2002) Äspö Hard Rock Laboratory. Prototype Repository - Installation of buffer, canisters, backfill and instruments in section 1. Technical Report, Stockholm

7. Conil N, Talandier J, Djizanne H et al. (2018) How rock samples can be representative of in situ condition: A case study of Callovo-Oxfordian claystones. Journal of Rock Mechanics and Geotechnical Engineering 10:613-623. doi: 10.1016/j.jrmge.2018.02.004

8. Cuisinier O, Laloui L (2004) Fabric evolution during hydromechanical loading of a compacted silt. Int J Numer Anal Meth Geomech 28:483-499. doi: 10.1002/nag.348

9. Cuisinier O, Masrouri F (2005) Hydromechanical behaviour of a compacted swelling soil over a wide suction range. Engineering Geology 81:204-212. doi: 
10. Delage P, Cui YJ (2008) An evaluation of the osmotic method of controlling suction. Geomechanics and Geoengineering 3:1-11. doi: 10.1080/17486020701868379

11. Delage P, Vicol T, Suraj de Silva, G. P. R. (1992) Suction controlled testing of non-saturated soils with an osmotic consolidometer. In: The proceedings of the 7th interna-tional conference on expansive soils. Texas Tech Universtiy Press, Lubbock, pp 206-211

12. Delage P, Howat M, Cui Y (1998) The relationship between suction and swelling properties in a heavily compacted unsaturated clay. Engineering Geology 50:31-48. doi:

\subsection{6/S0013-7952(97)00083-5}

13. Delage P, Romero E, Tarantino A (2008) Recent developments in the techniques of controlling and measuring suction in unsaturated soils. In: Toll DG, Augarde CE (eds) Unsaturated soils: Advances in Geo-Engineering. Proceedings of the 1st European Conference on Unsaturated Soils (E-UNSAT 2008, Durham, United Kingdom, 02/07/2008 04/07/2008). CRC Press/Balkema, Boca Raton, Fla., pp 33-52

14. Gallipoli D, Gens A, Sharma R et al. (2003) An elasto-plastic model for unsaturated soil incorporating the effects of suction and degree of saturation on mechanical behavior. Géotechnique 53:123-135. doi: 10.1680/geot.2003.53.1.123

15. Gao Y, Sun DA (2017) Soil-water retention behavior of compacted soil with different densities over a wide suction range and its prediction. Computers and Geotechnics 91:17-26. doi: 10.1016/j.compgeo.2017.06.016

16. Gao Y, Sun DA, Zhu Z et al. (2019) Hydromechanical behavior of unsaturated soil with different initial densities over a wide suction range. Acta Geotech 14:417-428. doi: $10.1007 / \mathrm{s} 11440-018-0662-5$

17. Gregg SJ, Sing KSW (1969) Adsorption, surface area and porosity, Second printing. Academic Press, London 
19. Hoffmann C, Alonso EE, Romero E (2007) Hydro-mechanical behaviour of bentonite pellet mixtures. Physics and Chemistry of the Earth, Parts A/B/C 32:832-849. doi:

$$
\text { 10.1016/j.pce.2006.04.037 }
$$

20. Juang CH, Holtz RD (1986) A probabilistic permeability model and the pore size density function. Int J Numer Anal Meth Geomech 10:543-553. doi: 10.1002/nag.1610100506

22. Likos WJ, Wayllace A (2010) Porosity evolution of free and confined bentonites during interlayer hydration. Clays Clay Miner 58:399-414. doi: 10.1346/CCMN.2010.0580310

23. Lloret A, Villar MV, Sánchez M et al. (2003) Mechanical behaviour of heavily compacted bentonite under high suction changes. Géotechnique 53:27-40. doi:

$$
\text { 10.1680/geot.2003.53.1.27 }
$$

24. Massat L, Cuisinier O, Bihannic I et al. (2016) Swelling pressure development and interaggregate porosity evolution upon hydration of a compacted swelling clay. Applied Clay Science 124-125:197-210. doi: 10.1016/j.clay.2016.01.002

25. Middelhoff M, Cuisinier O, Masrouri F et al. (2020) Combined impact of selected material properties and environmental conditions on the swelling pressure of compacted claystone/bentonite mixtures. Applied Clay Science 184:105389. doi:

$$
\text { 10.1016/j.clay.2019.105389 }
$$

26. Mitchell JK, Soga K (2005) Fundamentals of soil behavior, 3rd edition. John Wiley \& Sons, Hoboken, N.J.

27. Monroy R, Zdravkovic L, Ridley A (2010) Evolution of microstructure in compacted London Clay during wetting and loading. Géotechnique 60:105-119. doi: 10.1680/geot.8.P.125

28. Nagaraj TS, Murthy BRS, Vatsala A et al. (1990) Analysis of Compressibility of Sensitive Soils. Journal of Geotechnical Engineering 116:105-118. doi: 10.1061/(ASCE)07339410(1990)116:1(105) 
29. Nowamooz H, Masrouri F (2008) Hydromechanical behaviour of an expansive bentonite/silt mixture in cyclic suction-controlled drying and wetting tests. Engineering Geology 101:154-164. doi: 10.1016/j.enggeo.2008.04.011

30. Nowamooz H, Masrouri F (2009) Density-dependent hydromechanical behaviour of a compacted expansive soil. Engineering Geology 106:105-115. doi:

$$
\text { 10.1016/j.enggeo.2009.03.010 }
$$

31. Nowamooz H, Masrouri F (2010) Relationships between soil fabric and suction cycles in compacted swelling soils. Engineering Geology 114:444-455. doi: 10.1016/j.enggeo.2010.06.005

32. Orsini L, Remy JC (1976) Utilisation du chlorure de cobaltihexammine pour la détermination simultanée de la capacité d'échange et des bases échangeables des sols. Bulletin de l'AFES Science du Sol 4:269-275

33. Romero E (1999) Characterisation and thermo-hydro-mechanical behaviour of unsaturated boom clay. An experimental study. PhD-Thesis, Universitat Politècnica de Catalunya

34. Romero E (2013) A microstructural insight into compacted clayey soils and their hydraulic properties. Engineering Geology 165:3-19. doi: 10.1016/j.enggeo.2013.05.024

35. Romero E, Simms PH (2008) Microstructure Investigation in Unsaturated Soils: A Review with Special Attention to Contribution of Mercury Intrusion Porosimetry and Environmental Scanning Electron Microscopy. Geotech Geol Eng 26:705-727. doi: $10.1007 / \mathrm{s} 10706-008-9204-5$

36. Romero E, Gens A, Lloret A (1999) Water permeability, water retention and microstructure of unsaturated compacted Boom clay. Engineering Geology 54:117-127. doi: 10.1016/S0013-7952(99)00067-8 
633 37. Sivakumar V, Tan WC, Murray EJ et al. (2006) Wetting, drying and compression characteristics of compacted clay. Géotechnique 56:57-62. doi: 10.1680/geot.2006.56.1.57

38. Sun DA, Sheng DC, Cui HB et al. (2007) A density-dependent elastoplastic hydro-mechanical model for unsaturated compacted soils. Int J Numer Anal Meth Geomech

39. Wang Q, Tang AM, Cui Y-J et al. (2012) Experimental study on the swelling behaviour of bentonite/claystone mixture. Engineering Geology 124:59-66. doi:

40. Yigzaw ZG, Cuisinier O, Massat L et al. (2016) Role of different suction components on swelling behavior of compacted bentonites. Applied Clay Science 120:81-90. doi: 10.1016/j.clay.2015.11.022

41. Yuan S, Liu X, Sloan SW et al. (2016) Multi-scale characterization of swelling behaviour of compacted Maryland clay. Acta Geotech 11:789-804. doi: 10.1007/s11440-016-

44. Zhou A-N, Sheng D, Sloan SW et al. (2012) Interpretation of unsaturated soil behaviour in the stress-saturation space. Computers and Geotechnics 43:111-123. doi: 


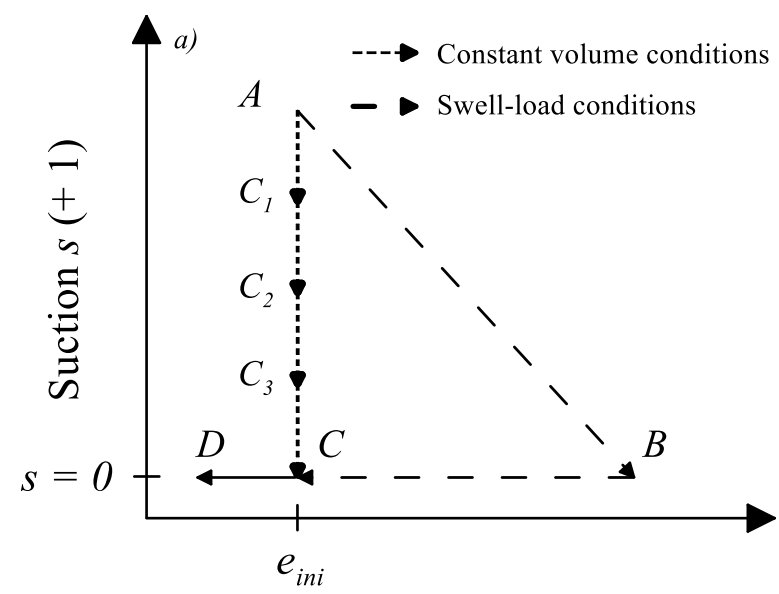

Void ratio $e$

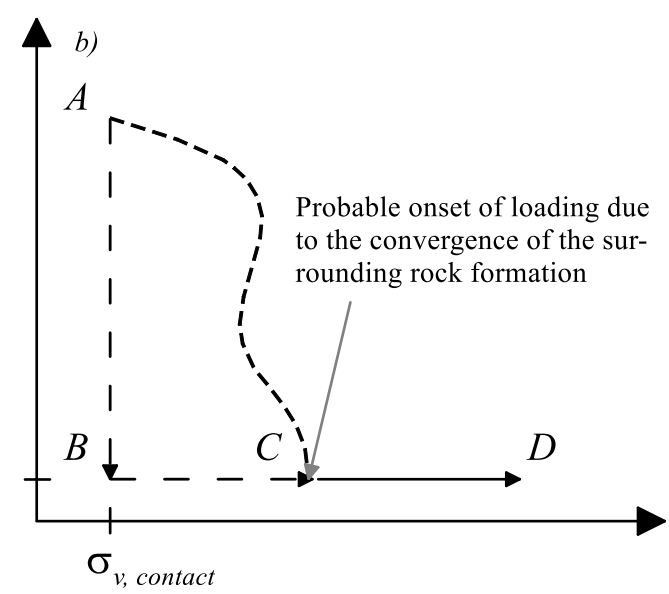

Vertical stress $\sigma_{v}$

658

659 Fig. 1 Possible combinations of hydraulic and mechanical paths subjected to the backfill upon terminat660 ing the installation phase 

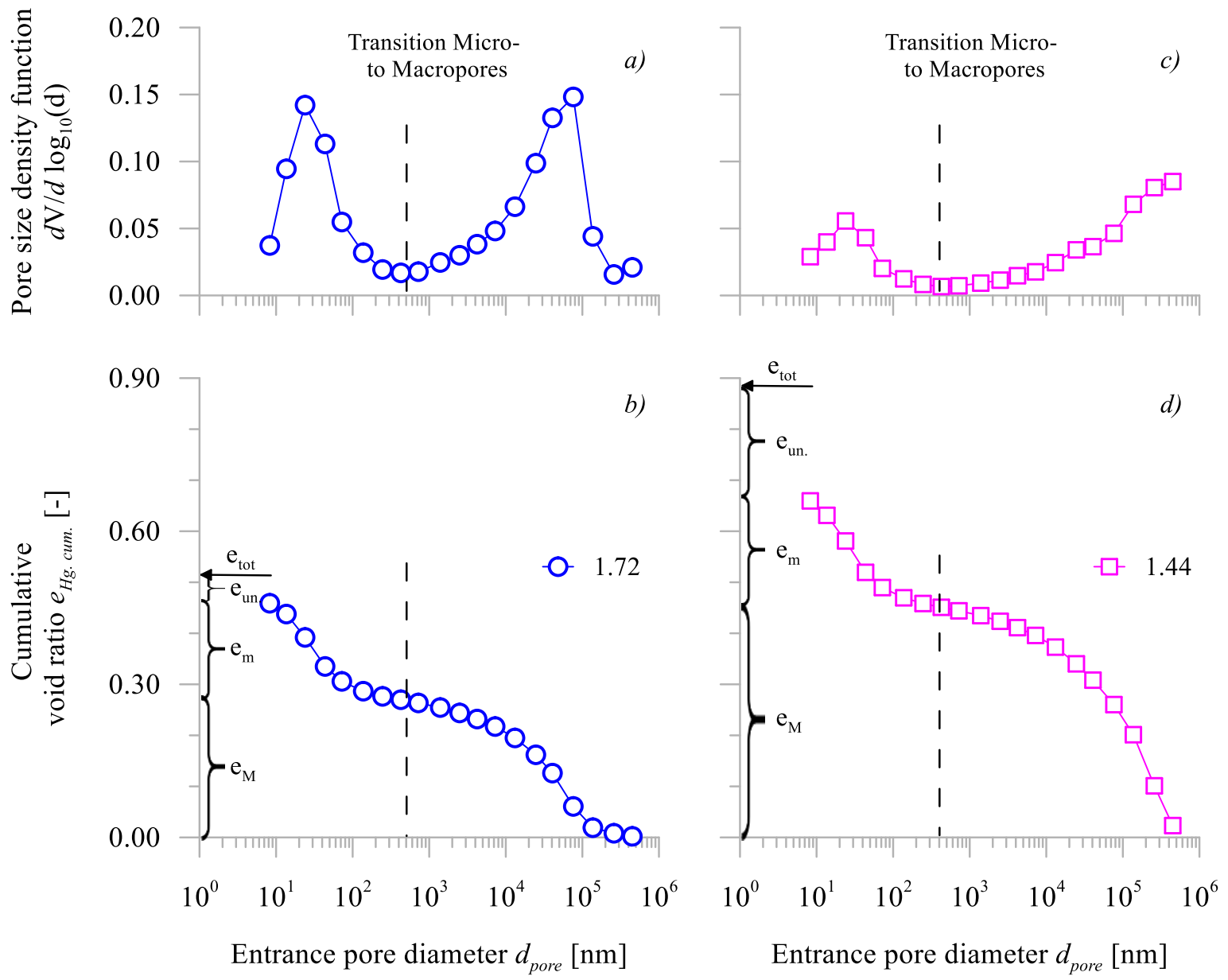

661

662 Fig. 2 Results of mercury intrusion porosimetry (MIP) experiments conducted on samples characterized 663 by initial dry densities of $\rho_{d, \text { ini }}=1.72 \mathrm{Mg} / \mathrm{m}^{3}$ and $\rho_{d, \text { ini }}=1.44 \mathrm{Mg} / \mathrm{m}^{3}$ 

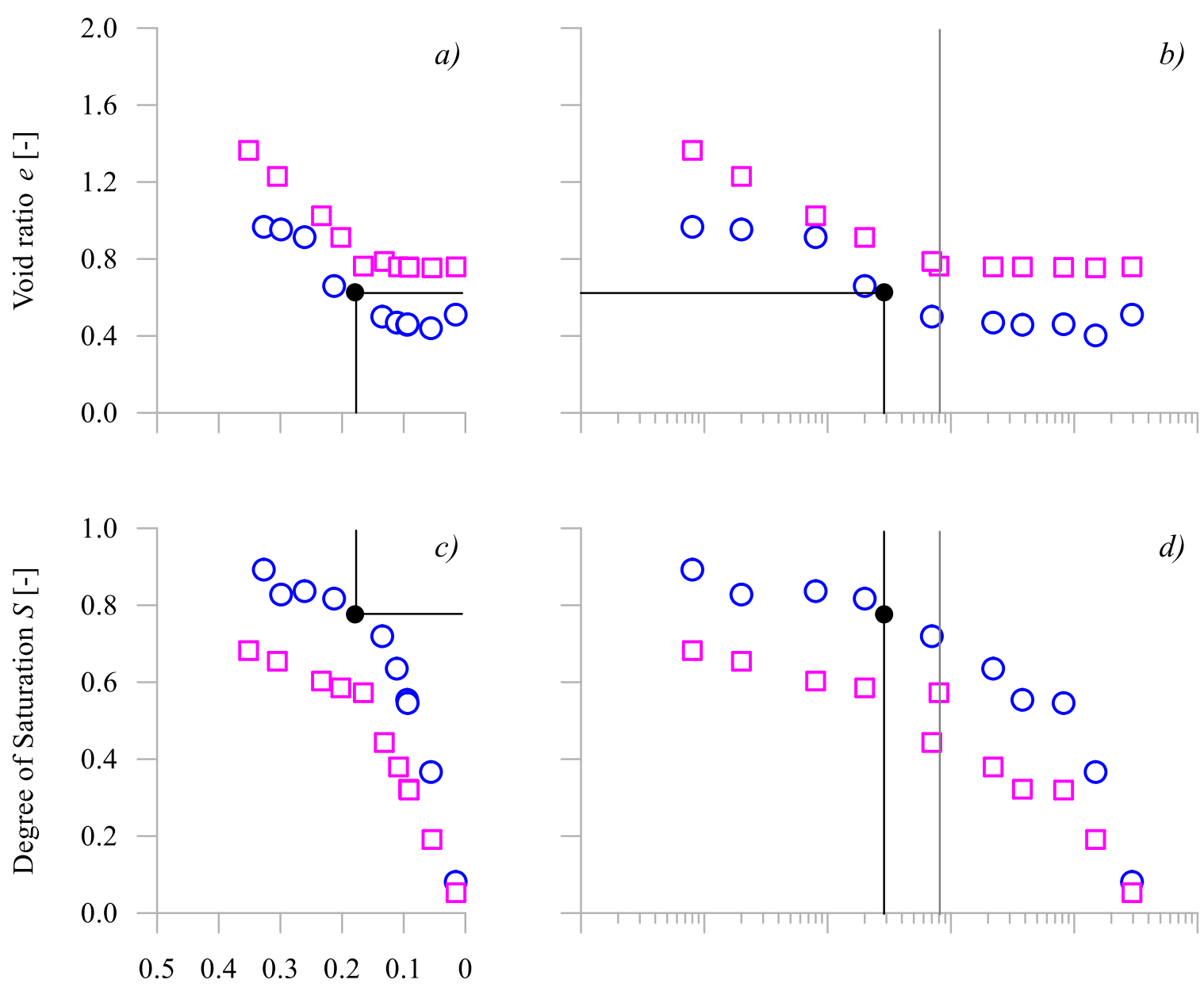

Water content $w[-]$

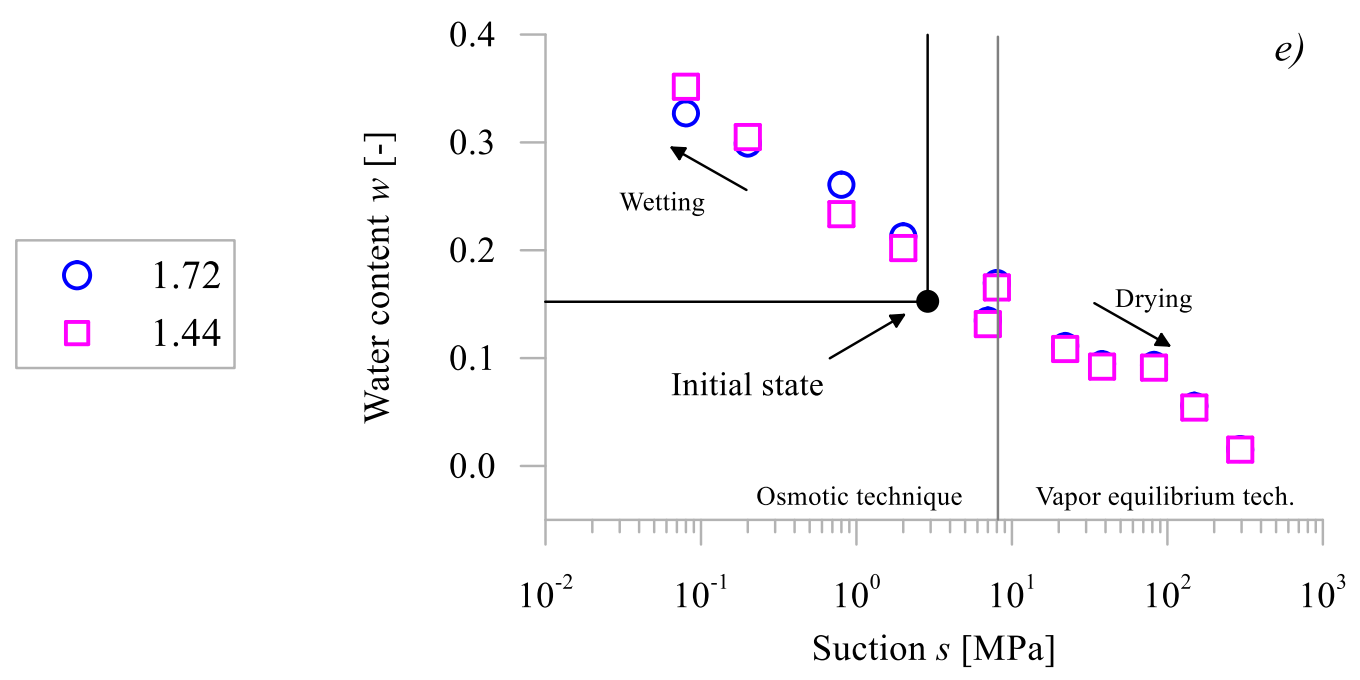

664

665 Fig. 3 Water retention characteristics of mixture samples characterized by initial dry densities of $\rho_{d, i n i}=$ $6661.72 \mathrm{Mg} / \mathrm{m}^{3}$ and $\rho_{d, \text { ini }}=1.44 \mathrm{Mg} / \mathrm{m}^{3}$ 


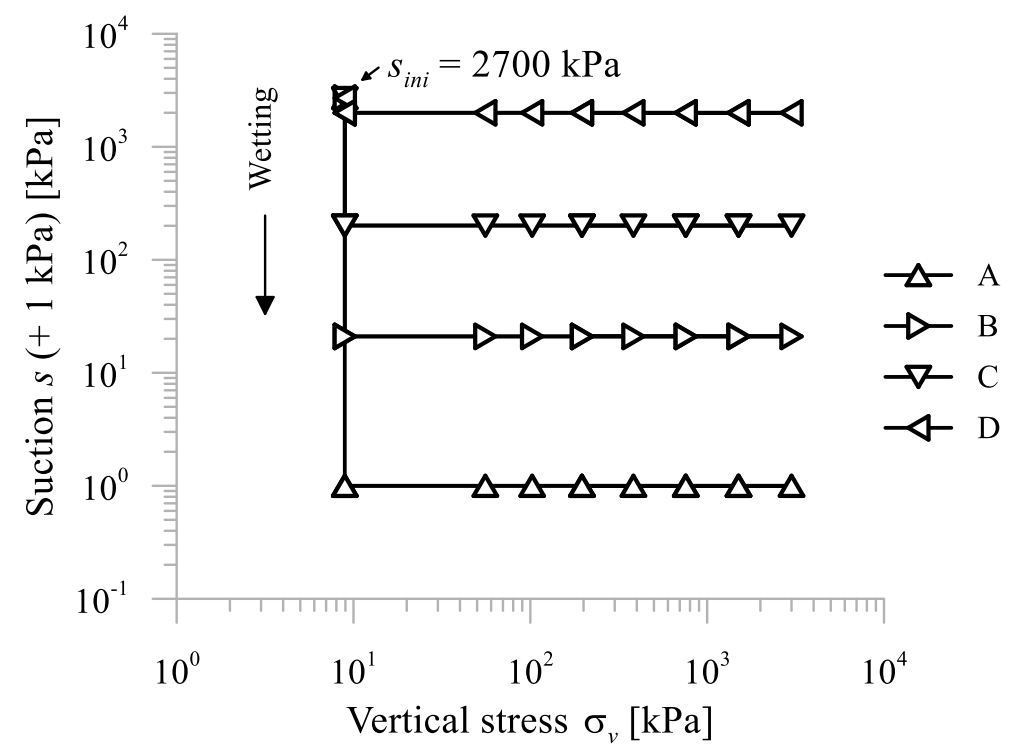

667

668 Fig. 4 Hydro-mechanical paths followed in suction-controlled oedometer experiments 

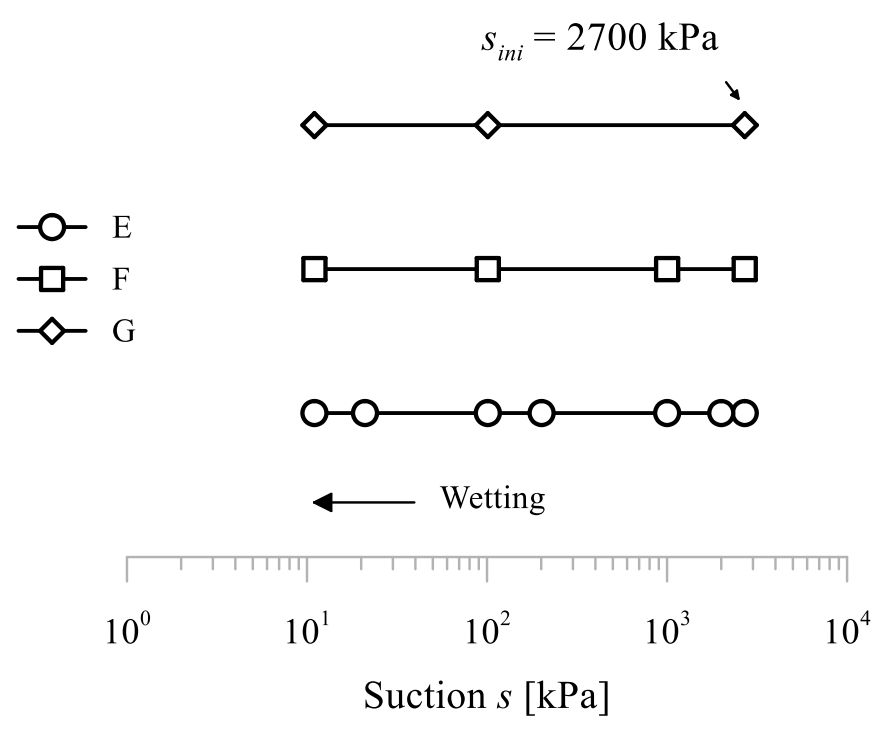

669

670 Fig. 5 Hydration paths followed in suction-controlled constant-volume swelling pressure experiments 

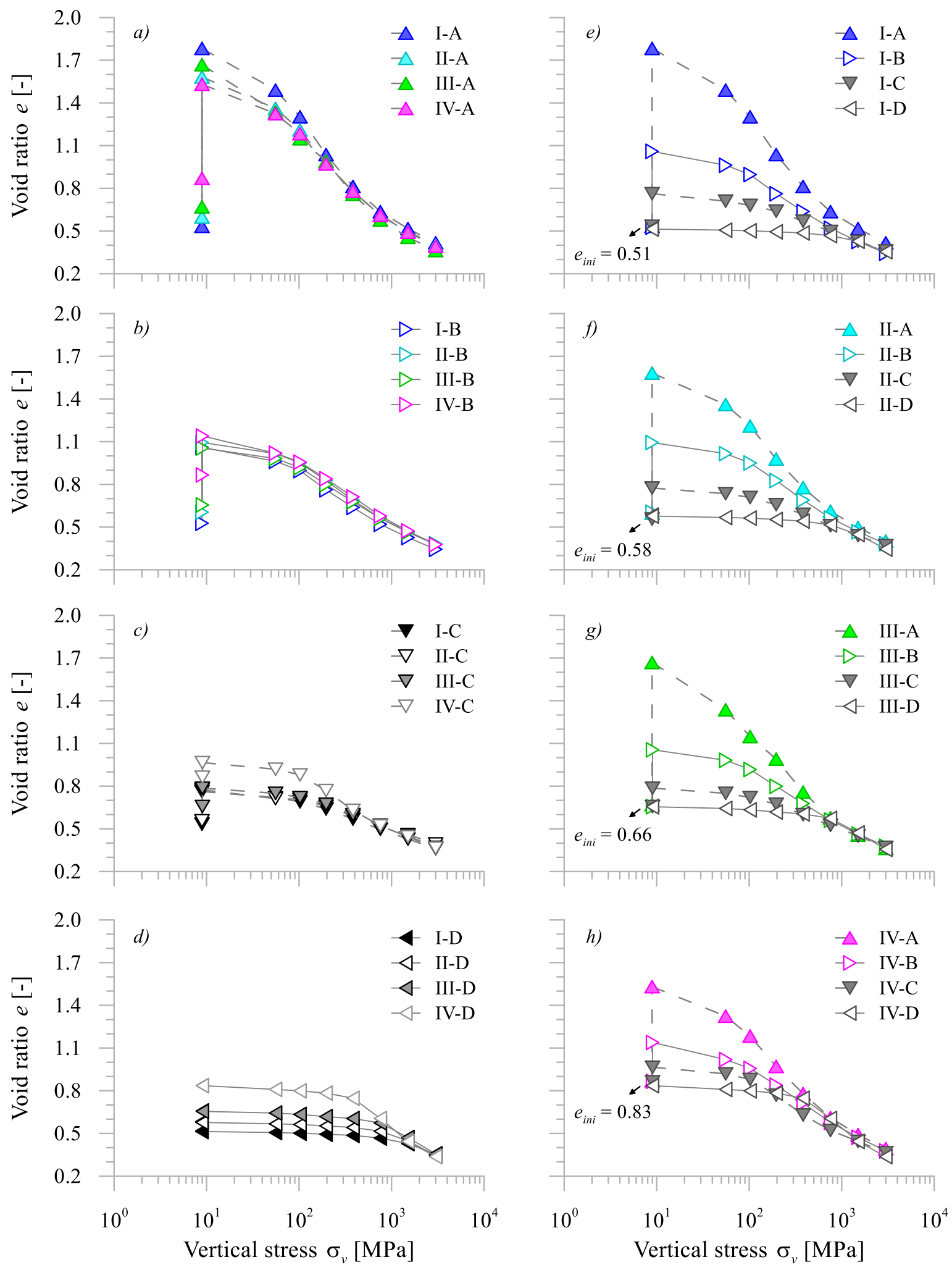

672 Fig. 6 Results of oedometer experiments conducted on samples characterized by different initial dry 673 densities (Fig. 6 a - d) upon imposing different hydro-mechanical paths (Fig. 6 e - h) 


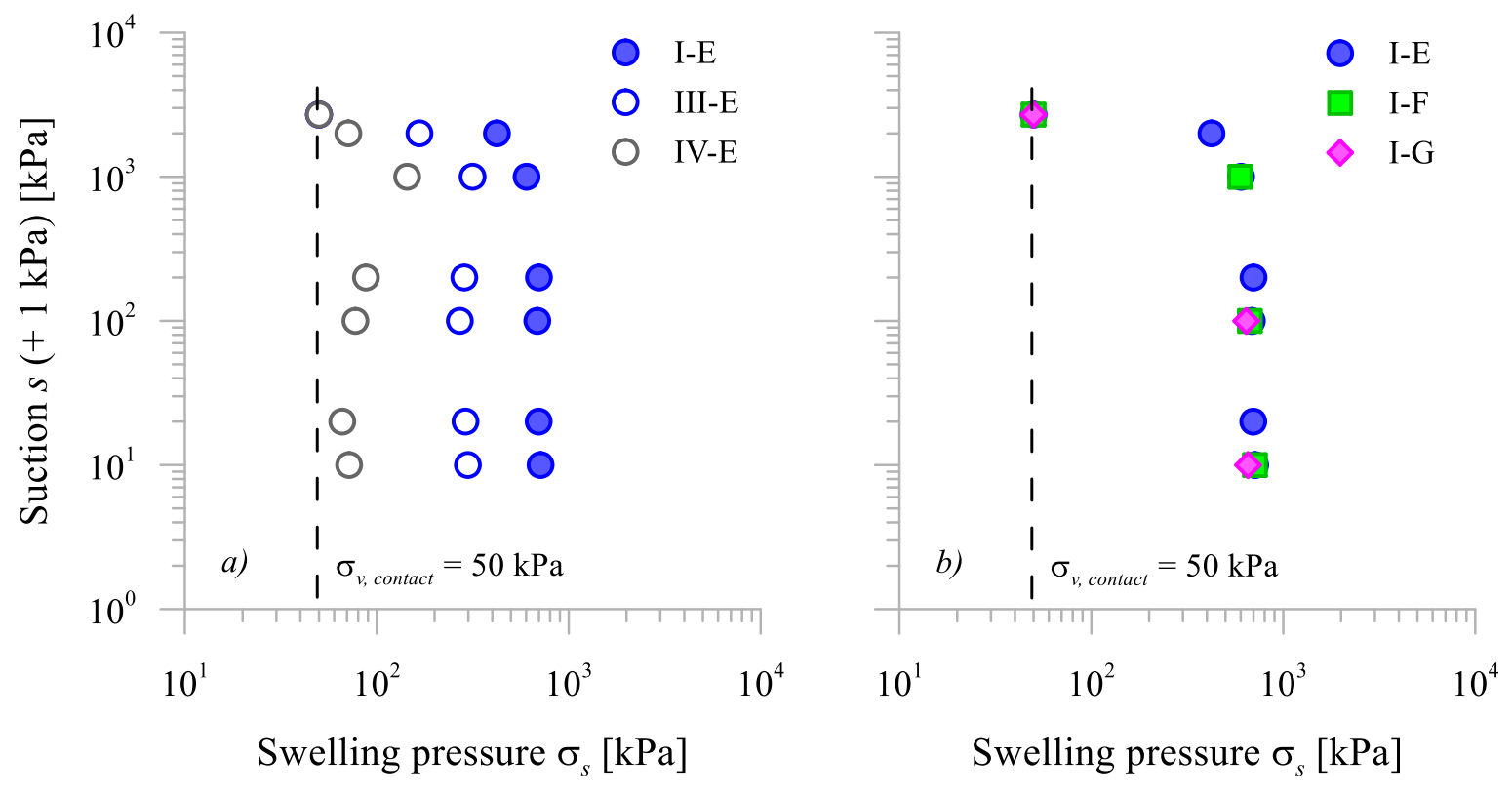

674

675 Fig. 7 Swelling pressure evolution of a) samples characterized by different initial dry densities upon 676 imposing hydration path $E$ and $b$ ) samples characterized by the same initial dry density upon imposing 677 hydration paths $E, F$, and $G$ 

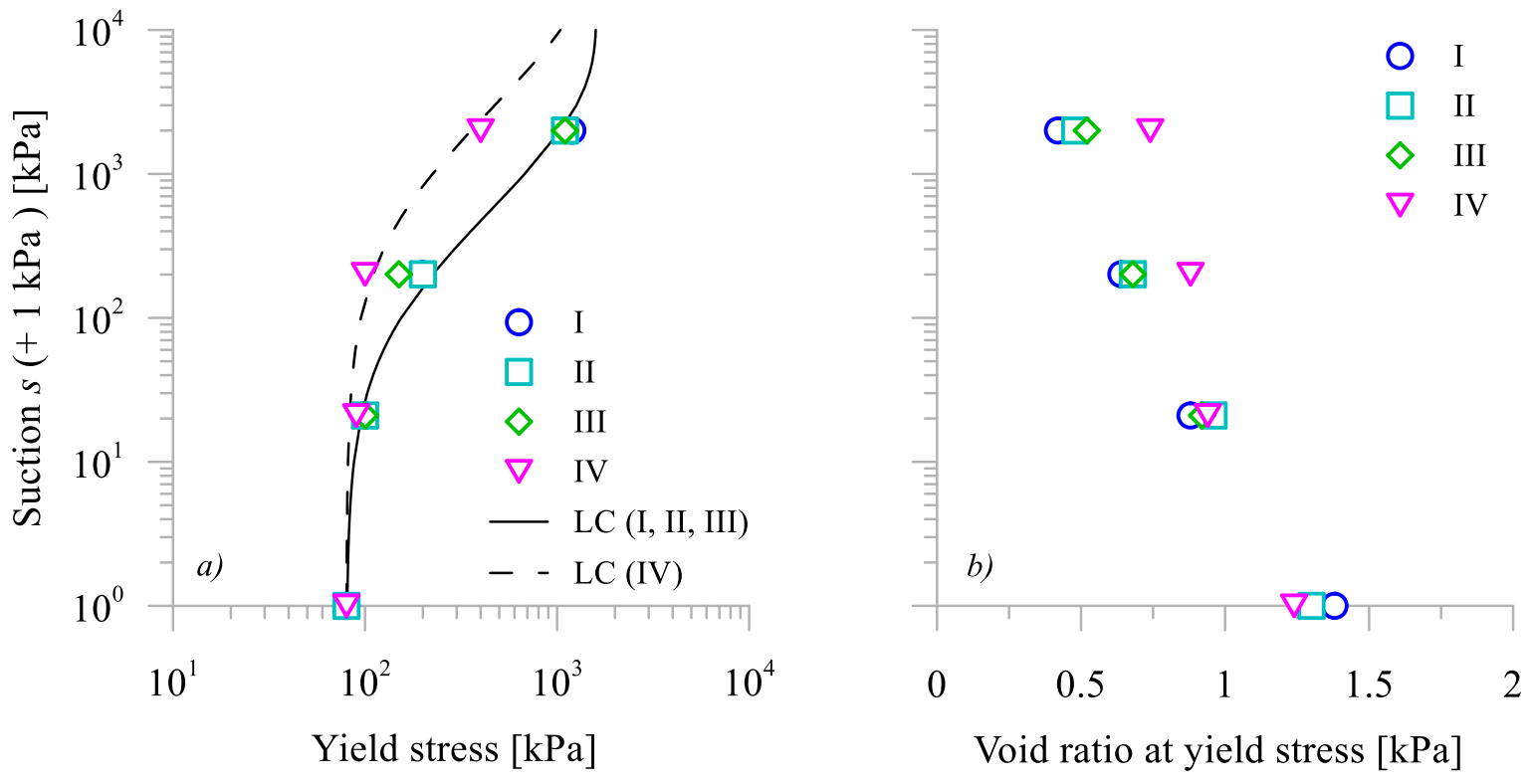

678

679 Fig. 8 Loading-collapse (LC) curves derived from suction-controlled oedometer experiments 


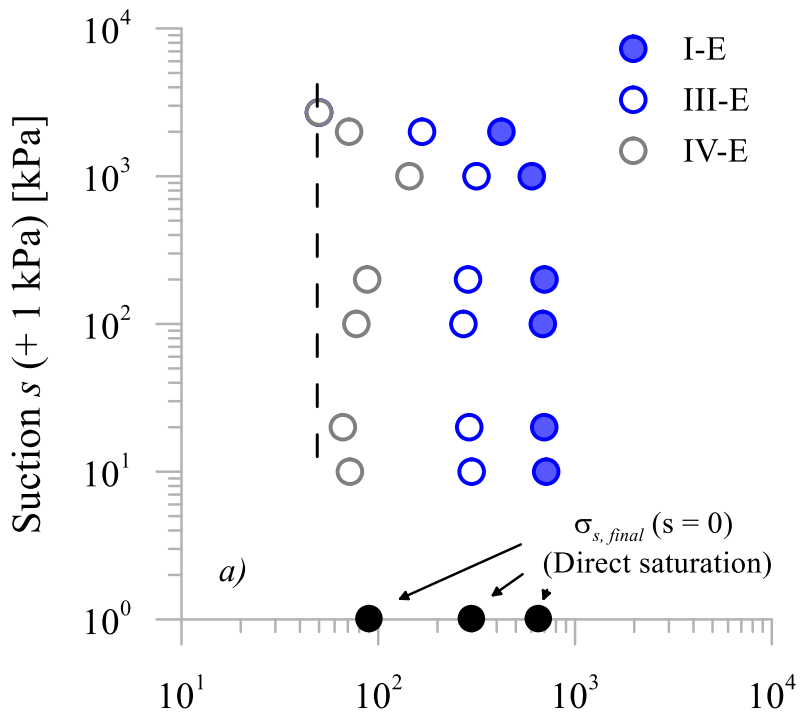

Swelling pressure $\sigma_{s}[\mathrm{kPa}]$

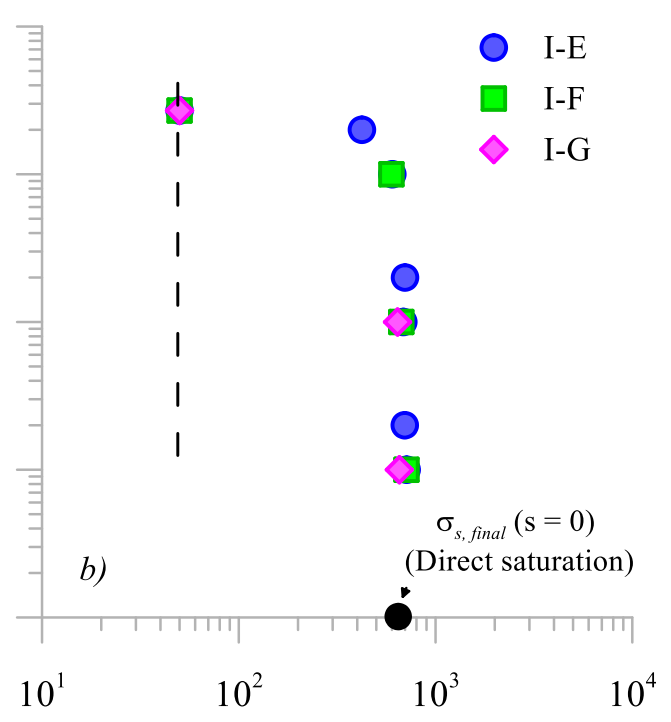

Swelling pressure $\sigma_{s}[\mathrm{kPa}]$

681 Fig. 9 Comparison between the swelling pressure evolution of a) samples characterized by the same 682 initial dry density upon saturating directly and imposing hydration paths $E$ and b) samples upon saturat683 ing directly and imposing hydration paths E, F, and G (Values of direct saturation were taken from [19]) 


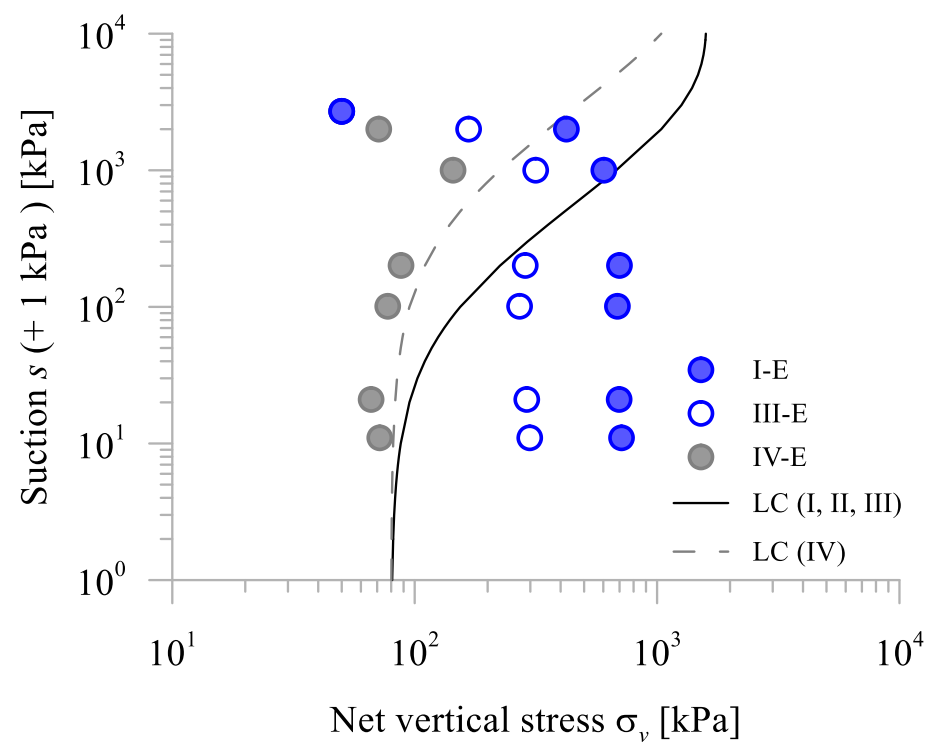

684

685 Fig. 10 Comparison between LC-curves derived from suction-controlled oedometer experiments and 686 swelling pressure evolution under constant-volume conditions 
687 Table 1 Initial characteristics of samples

\begin{tabular}{lllllll}
\hline Type & $\begin{array}{l}\text { Initial dry } \\
\text { density }\end{array}$ & $\begin{array}{l}\text { Initial water } \\
\text { content }\end{array}$ & $\begin{array}{l}\text { Initial void } \\
\text { ratio }\end{array}$ & $\begin{array}{l}\text { Initial poros- } \\
\text { ity }\end{array}$ & $\begin{array}{l}\text { Initial degree } \\
\text { of saturation }\end{array}$ & $\begin{array}{l}\text { Initial suc- } \\
\text { tion* }\end{array}$ \\
& $\rho_{d, i n i}$ & $w_{\text {ini. }}$ & $e_{\text {ini. }}$ & $n_{\text {ini. }}$ & $S_{\text {ini. }}$ & $S_{\text {ini. }}$ \\
{$\left[\mathrm{Mg}^{3}\right]$} & {$[-]$} & {$[-]$} & {$[-]$} & {$[-]$} & 0.90 & 2700 \\
\hline I & 1.72 & 0.182 & 0.53 & 0.35 & 0.82 & 0.73 \\
II & 1.66 & 0.182 & 0.59 & 0.37 & 0.56 & \\
III & 1.59 & 0.182 & 0.66 & 0.40 & 0.46 & 0.56 \\
IV & 1.44 & 0.182 & 0.86 & & \\
\hline
\end{tabular}

*: measured by means of chilled mirror method 
689 Table 2 Experiment program including microstructural and water retention analysis, suction-controlled 690 constant-volume swelling pressure and oedometer experiments

\begin{tabular}{llllllll} 
Sample type $^{l}$ & \multicolumn{2}{c}{ Oedometer experiments $^{2}$} & \multicolumn{3}{c}{ Swelling pressure experiments $^{3}$} \\
\hline & A & B & C & D & E & F & G \\
\hline I & $\checkmark$ & $\checkmark$ & $\checkmark$ & $\checkmark$ & $\checkmark$ & $\checkmark$ & $\checkmark$ \\
II & $\checkmark$ & $\checkmark$ & $\checkmark$ & $\checkmark$ & & \\
III & $\checkmark$ & $\checkmark$ & $\checkmark$ & $\checkmark$ & & \\
IV & $\checkmark$ & $\checkmark$ & $\checkmark$ & $\checkmark$ & & \\
\hline
\end{tabular}

${ }^{l}$ : compare Table 1

2: Hydro-mechanical paths (compare Fig. 4)

3 : Hydro-mechanical paths (compare Fig. 5)

691

692 